\title{
Validation and psychometric evaluation of the Dutch person-centred care of older people with cognitive impairment in acute care (POPAC) scale
}

Annette Keuning-Plantinga ${ }^{1,2,3^{*}}$, Evelyn J. Finnema ${ }^{1,2,3,4}$, Wim Krijnen ${ }^{4}$, David Edvardsson ${ }^{5,6}$ and Petrie F. Roodbol ${ }^{2,3}$

\begin{abstract}
Background: Person-centred care is the preferred model for caring for people with dementia. Knowledge of the level of person-centred care is essential for improving the quality of care for patients with dementia. The person-centred care of older people with cognitive impairment in acute care (POPAC) scale is a tool to determine the level of personcentred care. This study aimed to translate and validate the Dutch POPAC scale and evaluate its psychometric properties to enable international comparison of data and outcomes.

Methods: After double-blinded forward and backward translations, a total of 159 nurses recruited from six hospitals $(n=114)$ and via social media $(n=45)$ completed the POPAC scale. By performing confirmatory factor analysis, construct validity was tested. Cronbach's alpha scale was utilized to establish internal consistency.

Results: The confirmatory factor analysis showed that the comparative fit index (0.89) was slightly lower than 0.9. The root mean square error of approximation $(0.075, p=0.012, \mathrm{Cl} 0.057-0.092)$ and the standardized root mean square residual $(0.063)$ were acceptable, with values less than 0.08 . The findings revealed a three-dimensional structure. The factor loadings (0.69-0.77) indicated the items to be strongly associated with their respective factors. The results also indicated that deleting Item 5 improved the Cronbach's alpha of the instrument as well as of the subscale 'using cognitive assessments and care interventions'. Instead of deleting this item, we suggest rephrasing it into a positively worded item.

Conclusions: Our findings suggest that the Dutch POPAC scale is sufficiently valid and reliable and can be utilized for assessing person-centred care in acute care hospitals. The study enables nurses to interpret and compare personcentred care levels in wards and hospital levels nationally and internationally. The results form an important basis for improving the quality of care and nurse-sensitive outcomes, such as preventing complications and hospital stay length.
\end{abstract}

Keywords: Acute care, Dementia, Nurses, Person-centred care, Psychometrics, Quality of care

\footnotetext{
* Correspondence: annette.keuning@nhlstenden.com

${ }^{1} \mathrm{NHL}$ Stenden University of Applied Sciences, Rengerslaan 8-10, Postbox 1298, 8900, CG, Leeuwarden, The Netherlands

${ }^{2}$ Health Sciences-Nursing Science \& Education University of Groningen \&

University Medical Center Groningen, Hanzeplein 1, Postbox 30.001, 9700, RB, Groningen, The Netherlands

Full list of author information is available at the end of the article
}

(c) The Author(s). 2021 Open Access This article is licensed under a Creative Commons Attribution 4.0 International License, which permits use, sharing, adaptation, distribution and reproduction in any medium or format, as long as you give appropriate credit to the original author(s) and the source, provide a link to the Creative Commons licence, and indicate if changes were made. The images or other third party material in this article are included in the article's Creative Commons licence, unless indicated otherwise in a credit line to the material. If material is not included in the article's Creative Commons licence and your intended use is not permitted by statutory regulation or exceeds the permitted use, you will need to obtain permission directly from the copyright holder. To view a copy of this licence, visit http://creativecommons.org/licenses/by/4.0/ The Creative Commons Public Domain Dedication waiver (http://creativecommons.org/publicdomain/zero/1.0/) applies to the data made available in this article, unless otherwise stated in a credit line to the data. 


\section{Background}

Worldwide, approximately 50 million people are living with dementia. Due to the ageing population, this number will increase [1]. People with dementia are regularly hospitalized due to comorbidities; they occupy approximately $25 \%$ of the hospital beds [2,3]. This population is at risk for falls during a hospital stay, inadequate hydration and nutrition, delirium, infection, and functional decline [4-6]. These factors impact the duration of stay, the person's functioning, and the care required following discharge [7]. Nursing care for people with dementia should be based on evidence, best-practice care, and processes combined with person-centred care to prevent complications $[6,8-11]$. It is known that person-centred care can improve their quality of life. In spite of that, specific knowledge about person-centred care, also referred to as patient-centred or client-centred care, is limited in hospitals [11]. However, worldwide, it is the paragon in the care of people with dementia [10, 12]. The basis of person-centred care in caring for people with dementia is laid by Tom Kitwood [13, 14]. In a broader context, the framework of McCormack ad McCance is often used [15-17]. In the care for people with dementia, Brooker's definition and framework are often used $[3,18]$.

To improve the quality of care for people with dementia in an acute care setting, knowledge of the level of person-centredness of the care is important. The literature reports a limited number of instruments that measure person-centred care for dementia patients in an acute hospital setting $[8,19]$. Available instruments are aimed at long-term care [20] or more generically on person-centred care in the acute hospital setting and lack a specific focus on the quality of care for people with dementia [21-24].

The person-centred care of older people with cognitive impairment in acute care (POPAC) scale [19] was developed for the acute hospital setting and measures the person-centredness of care for older people with dementia. The scale consists of three subscales, which can be connected to the elements of person-centred care of the definition used. The subscale 'using cognitive assessments and care interventions' is suitable for valuing people; 'using evidence and cognitive expertise' is suitable for understanding situations from the perspective of the person with dementia; and 'individualizing care' is related to individualizing approaches and the social environment. In addition to measuring and improving the quality of care, translating tools into different language versions enables international comparisons of data and comparative analysis of levels, correlations, and personcentred care outcomes. In addition, there are no Dutchlanguage instruments available that measure personcentred care in the hospital setting.
The POPAC scale was designed in 2013 by Edvardsson in Australia to establish quantitative measurements to assess experienced levels of person-centred care for people with dementia in acute hospital settings [19, 25]. Based on the literature, eight dimensions of best practice were used to construct the instrument. Further development with a panel of international experts led to an instrument that consisted of statements on recognizing cognitive impairment, consulting specialist expertise, using evidence-based care protocols or guidelines, making environmental adjustments, providing social enrichments, prioritizing staff continuity and close interactions, avoiding restraints, and individualizing care [19]. The degree to which participants agree with item statements was expressed on a 6-point Likert scale with the categories 'never' [1], 'very rarely' [2], 'rarely' [3], 'frequently' [4], 'very frequently' [5], and 'always' [6] [10, 19, 25]. A significant Bartlett's spherical test and a Kaiser-Meyer-Olkin (SME) sample adequacy measurement of $>0.7$ were used to assess the construct validity. Construct validity was then assessed using principal component analysis with oblimin rotation due to the factors' expected correlation [19].

The original instrument was pilot tested with a sample of 212 nurses from different types of wards, such as neurology, orthopaedics, and cardiology, in an acute care hospital in Melbourne, Australia. After the preliminary test, six items were removed because they did not meet the cutoff for acceptable homogeneity $(>0.3)$. A retest was conducted with 25 nurses from an orthopaedic ward, and the outcomes indicated satisfactory temporal stability [19]. The assumption that all items reliably measure a single underlying construct was supported by the item-total correlations ranging from 0.40 to 0.67 , where values 0.4 and above indicate very good discrimination [26]. The subscales can be combined into a total score, where higher scores indicate higher personcentredness levels to evaluate the overall level of personcentred care. An interpretation of the score is not yet available. The totals of the items per subscale suggest possible areas for improvement of care. The instrument allows the comparison of person-centred care at both national and international levels [19].

Nilsson psychometrically evaluated the instrument in Sweden (2013), and Grealish (2017) evaluated the scale in Australia [10, 25]. Both Nilsson and Grealish used Cronbach's alpha and corrected total correlation for internal consistency and CFA for construct validity. In addition, in Nilsson's study, temporal stability was measured through the correlation between test and retest scores [10]. Both studies reported that the POPAC scale is valid and reliable and can be used to provide insight into nursing care's person-centredness in a hospital setting. However, the high correlations between the subscales and the authors' conclusion that the instrument's 
dimensionality requires further research are important tenets for this study $[10,25]$. For using the POPAC scale in the Netherlands to study person-centred care in a hospital setting, the instrument needed to be translated into Dutch. Measuring psychometric properties is important for assessing validity and reliability [27]. Nurses and nursing managers can use the outcomes of the POPAC scale to improve the quality of care in their ward, and outcomes and data can be used for national and international comparison. Therefore, this study aimed to conduct a cross-national validation and psychometric evaluation of the Dutch version of the POPAC scale.

\section{Methods}

This study aimed to translate and validate the POPAC scale into Dutch and test the Dutch version of the questionnaires for psychometric properties among Dutch nurses working in acute hospital settings [28]. Data were collected with the online questionnaire program Qual$\operatorname{trics}^{\mathrm{XM}}$ (version 2018, Provo, UT USA).

\section{The instrument}

The POPAC scale consists of 15 items, as shown in Table 1 . The items describe care procedures and processes in patients with dementia in hospitals [19]. With the self-report of nurses in hospitals, the POPAC scale measures the extent to which nursing interventions are based on best practices in association with personcentred care. The items are divided into three subscales: cognitive assessments and care interventions (items 15), evidence and cognitive expertise (items 6-8), and individualizing care (items 9-15) [19]. The scores can be evaluated per subscale, or the score of the total scale can be used. The subscale or total scale scores can be calculated by dividing the sum of the scores by the number of items, whereby higher scores imply higher levels of person-centredness $[10,19,25]$.

\section{Translation of the person-centred care of older people with cognitive impairment on the acute care scale}

The instrument's principal author was involved in the translation, validation, and writing of the evaluation. Therefore, the instrument was translated according to the guidelines described by Sousa [29]. Two independent translators from a certified translation agency translated the questionnaire into Dutch. Two researchers (AK and EJF) independently assessed these two translations to determine the optimal translation of the question formulations and the answer options.

During the translation process, there was some discussion about using the term 'cognitive functioning' or 'cognitive status', whereby all translators agreed upon the choice for 'cognitive functioning' because this term is
Table 1 Original items POPAC (Edvarsson, 2013) [19]

Item

1 We assess the cognitive status of our older patients on admission

2 We make environmental adjustments to avoid over-stimulation in older people with cognitive impairment (e.g. single rooms, noise reductions etc.)

3 We diagnose symptoms of cognitive impairment (e.g. dementias, delirium etc.)

4 We spend more time with older patients with cognitive impairments as compared to cognitively intact patients

5 We leave older people with cognitive impairments alone in the ward

6 We use evidence-based tools to assess cognitive status of older patients (e.g. the MMSE, SPMSQ, CAM)

7 We consult specialist expertise (e.g. psychologist, gerontologist) if we find that a patient has cognitive impairment

8 We use evidence-based care guidelines in the care of older cognitively impaired patients

9 We use biographical information about older patients (e.g. habits, interests and wishes etc.) to plan their care

10 We involve family members in the care of older patients with cognitive impairment

11 We provide staff continuity for older patients with cognitive impairments (e.g. the same nurses providing care to these patients as often as possible)

12 We systematically evaluate whether or not older patients with cognitive impairment receive care that meets their needs

13 We involve older patients with cognitive impairment in decisions about their care (e.g. examinations, treatments etc.)

14 We ensure that older patients with cognitive impairment have tests/examinations/consultations in the unit rather than having to go to another department

15 We discuss ways to meet the complex care needs of people with cognitive impairment

commonly used in nursing care in the Netherlands. There were no disagreements on a lingual or cultural basis. There was unanimous consensus for the final selection of all items.

This Dutch version was also translated back into English by two other independent translators from the same certified translation agency. These translations were again independently assessed by the same researchers to decide on the best translation. This time, there was consensus on all of the items. The author reviewed this final English version, and the conclusion was that the outcomes closely resembled the original version. There were no specific reasons to expect systematic errors during the translation due to linguistic or cultural differences [30]. The final version is attached as Additional file 1.

\section{Sample size}

According to the scientific literature, the sample size depends on the number of factors and the factor load, where a minimum sample size of 100 is recommended, 
and a sample size of 150 is suggested for three-phase models [30, 31]. The COSMIN (Consensus-based Standards for the selection of health status measurement instruments) checklist advocates seven times the number of items [32]. Based on this knowledge, the optimal sample size was at least 150 [33, 34]. It may be noted that in the post hoc analysis, the sample size was sufficient for almost all estimated parameters to be (highly) significant.

\section{Setting, recruitment, and participants}

Six hospitals in the northern part of the Netherlands participated in this study and were supplemented by Dutch nurses who were recruited via LinkedIn and Facebook. The data were collected in one university hospital, two non-university teaching hospitals, and three rural hospitals. The capacity of the hospitals varied from 241 to 1300 beds, with additional outpatients.

Nurses with at least three months of experience in the clinical setting, working in the direct care of people with dementia, and willing to participate were included in the study. All hospital departments were included, except for paediatrics and obstetrics. The data collection took place from July 2018 to March 2019.

The recruitment of participants in the hospitals was performed by contact persons working in the hospital based on a convenience sample [27]. The authors also used LinkedIn and Facebook to recruit hospital nurses. A general request was made for nurses to participate via LinkedIn, in which nursing managers are active and then the call was repeated once. For Facebook, which is often used by Dutch nurses, a different approach was used for which the authors requested two groups on Facebook. One was in a private group for questionnaires of a professional nursing magazine, and the other was in an open group for nurses in general. On Facebook, a daily update of the response was provided. This Facebook group has many members; however, it is not known how many members are active.

\section{Data analysis}

For the data analysis, we used IBM SPSS statistics (for Macintosh, version 25, Armonk, NY: IBM Corp.). Only complete scales were used in the data analysis. To perform confirmatory factor analysis (CFA), JASP (Version 0.11.1) with Lavaan was used [33]. Before starting the analysis, Item 5 was reverse coded due to the negative wording of this item. The decision to use only completed scales was made based on the response rate of 159 complete cases instead of 164 with the inclusion of incomplete scales. Because the sample was sufficiently large and the differences in outcomes were minimal, it was decided that only completed questionnaires would be included. This makes the data as accurate as possible.
The Shapiro-Wilk test was used to assess the normality of the distribution. Descriptive analyses were used to describe the sample. Item performance was assessed by calculating item means and standard deviations, the inter-item correlation matrix, and the corrected itemtotal correlation.

The CFA was performed by robust maximum likelihood estimation, after which four types of fit indices were used to evaluate the fit of the model to the data: the chi-square model fit, the comparative fit index (CFI), the root mean square error of approximation (RMSEA), and the standardized root mean-square residual (SRMR). The Hoelter index was utilized to check the smallest sample size at which the chi-square interpretation would not be significant. As a criterion for significance, a $p$ value $<0.05$ was used. The model fit was considered acceptable if the following criteria were met: p-value for the $\mathrm{x} 2$ model fit compared to the baseline model smaller than 0.05 , CFI and GFI values between 0.90 and 0.95 or above RMSEA and RMR values of 0.08 or below [34].

Cronbach's alpha on the total scale and its subscales were assessed to determine the internal consistency.

\section{Ethics approval and consent to participate}

The study was performed following the Helsinki declaration, and all of the participants provided written informed consent before filling out the questionnaire. Nurses had an option to choose whether the results would also be available for further research. The Medical Ethical Committee of the University Medical Center Groningen considered approval unnecessary (decision M17.221048) because the questionnaire was intended for staff. The questionnaire was completely anonymous; no one could be identified based on the results. The managers received an email with a general explanation and a link to the questionnaire to forward it to the nurses of their team. Managers were not informed about the number of participating nurses from their ward or about their responses. Based on the contact persons' information and the response per ward, there was no reason to believe that nurses felt obliged to participate in this survey. The voluntary nature of participation was emphasized in the explanations.

\section{Results}

\section{Characteristics of the sample}

In total, 159 hospital nurses completed the POPAC scale; 114 nurses were recruited directly from hospitals, and 45 nurses were recruited through social media. The hospitals' general response rate was $33 \%$, based on the managers of the participating wards' information. More specifically, responses came from nurses working in medical (21.4\%), surgical (20.1\%), and geriatric $(13.2 \%)$ wards as well as in wards with different combinations of 
specialized care $(45.3 \%)$, as shown in Table 2 . The education of the nurses varied from a care assistant level to a master level. The nurses had an average experience of 18 years of working with the elderly population, ranging from a few weeks to 45 years (SD 12.6). A total of $43.3 \%$ of the nurses had participated in a course in the past year about care for people with dementia. They graded their skills on caring for people with dementia with an average of 7.3 on a scale from 1 to 10 with a range from 4 to 9 (SD 0.095).

\section{Item performance}

The mean score per item varied between 3.59 and 5.28, as shown in Table 3. The total score was 66.88 (SD 10.04), with a mean of 4.46 (SD 0.53). The Shapiro-Wilk test indicated that the data were skewed. The skewness per item varied between -0.04 and -1.83 . Internal consistency was based on a cutoff point of Cronbach's alpha 0.7, an item-total correlation of 0.3, and inter-item correlations between $0.2-0.4$ [26]. The correlation between the different items revealed some negative correlations with Item 5. It shows a corrected item-total correlation of 0.11 . The other values varied from 0.34 (Item 14) to 0.63 (Items 8 and 9). The Cronbach's alpha increased by 0.1 when Item 5 was deleted. The visual expectation of the data gave indications for a three-block structure.

\section{Construct validity}

Construct validity was evaluated with the CFA loadings for the items and the interfactor correlations based on ML estimation. Lavaan's iterative maximum likelihood estimation converged after 22 iterations. An overview of the different fit indices is shown in Table 4 and indicates an acceptable model fit. The Hoelter's critical $\mathrm{N}$ was 106.8, which means that the sample size was adequate.

A chi-square test was performed to check the model fit. This test showed that the factor model differed significantly from the baseline model, $\chi^{2}(87, N=159)=164$, $84, p<.001$. The obtained CFI of 0.89 was slightly smaller than the cutoff value of 0.9. Both the RMSEA $(0.075, p=$ 0.012, CI 0.057-0.092) and the SRMR of 0.063 were acceptable, with values less than 0.08 .

The CFA showed that all loadings were fairly large, positive, and significantly different from zero, as presented in Table 5 with Item 5 as the only exception. The factor correlations were between 0.69 and 0.77 , indicating that the factors were strongly associated.

Figure 1 provides the final model with significant correlations between the subscales, residual variances, and factor covariances.

\section{Internal consistency}

For measuring internal consistency, Item 5 was reversed. The total instrument's internal consistency measured by Cronbach's alpha was 0.85 (CI 0.82-0.88). The internal consistency of using cognitive assessments and care interventions was 0.60 (CI $0.45-0.66$ ) with item five and 0.72 (CI 0.63-0.78) without it; using evidence and cognitive expertise had an internal consistency of 0.78 (CI 0.70-0.83) and individualizing care 0.8 (CI 0.74-0.84).

\section{Discussion}

This study aimed to translate and validate the Dutch version of the POPAC scale and evaluate the psychometric properties to make international comparisons possible.

Table 2 Characteristics of nurses ( $n=159$ )

\begin{tabular}{|c|c|c|c|c|c|c|c|}
\hline & & \multicolumn{2}{|c|}{ Directly from hospital } & \multicolumn{2}{|c|}{ Via Social Media } & \multicolumn{2}{|l|}{ Total } \\
\hline & & Frequency & Percent & Frequency & Percent & Frequency & Percent \\
\hline \multirow[t]{5}{*}{ Level of nurses } & Student level & 0 & 0 & 1 & 2.2 & 1 & 0.6 \\
\hline & Care assistant & 1 & 0.9 & 1 & 2.2 & 2 & 1.3 \\
\hline & Secondary vocational level & 60 & 53.5 & 24 & 53.3 & 64 & 52.8 \\
\hline & Bachelor level & 52 & 46.6 & 8 & 17.8 & 60 & 37.7 \\
\hline & Master level & 1 & 0.9 & 11 & 24.4 & 12 & 7.6 \\
\hline \multirow[t]{5}{*}{ Ward type } & Medical & 17 & 14.9 & 17 & 37.8 & 34 & 21.4 \\
\hline & Surgical & 23 & 20.2 & 9 & 20 & 32 & 20.1 \\
\hline & Geriatric & 17 & 14.9 & 4 & 8.9 & 21 & 13.2 \\
\hline & Other & 57 & 50 & 15 & 33.3 & 72 & 45.3 \\
\hline & & Mean & SD & Mean & SD & Mean & SD \\
\hline Years' experience in working with elderly & & 19.7 & 12,7 & 13,7 & 11.15 & 18 & 12.6 \\
\hline Grade skills & & 7.1 & 1,5 & 7.2 & 1.1 & 7.2 & 1.8 \\
\hline \multirow[t]{2}{*}{ Followed a course on dementia last year } & Yes & 50 & 43.8 & 19 & 42.2 & 69 & 43.4 \\
\hline & No & 64 & 56.1 & 26 & 57.8 & 90 & 56.6 \\
\hline
\end{tabular}


Table 3 Median (SD), Mean (SD), Item-rest correlation, Item-total correlation, Cronbach's alpha if item deleted, Cronbach's alpha overall, and Cronbach's alpha per subscale $(n=159)$

\begin{tabular}{|c|c|c|c|c|c|c|c|c|c|c|}
\hline & Median & $S D^{a}$ & $\mathrm{IQR}^{\mathrm{b}}$ & Mean & $S D^{a}$ & $\begin{array}{l}\text { Item-rest } \\
\text { correlation }\end{array}$ & $\begin{array}{l}\text { Item-total } \\
\text { correlation }\end{array}$ & $\begin{array}{l}\text { Cronbach's alpha if } \\
\text { item deleted }\end{array}$ & $\begin{array}{l}\text { Cronbach's } \\
\text { alpha overall }\end{array}$ & Cronbach's alpha per subscale \\
\hline Item1 & 6 & 1.05 & 1 & 5.28 & 1.06 & 0.48 & 0.54 & 0.84 & \multirow[t]{15}{*}{0.85} & \multirow{5}{*}{$\begin{array}{l}\text { 1. Using cognitive assessments } \\
\text { and care interventions } \\
\text { with item } 5: 0.60 \\
\text { without item } 5: 0.72\end{array}$} \\
\hline Item2 & 5 & 1.05 & 1 & 4.75 & 1.05 & 0.56 & 0.67 & 0.84 & & \\
\hline Item3 & 5 & 1.06 & 2 & 4.90 & 1.06 & 0.46 & 0.49 & 0.84 & & \\
\hline Item4 & 4 & 1.20 & 2 & 3.87 & 1.20 & 0.43 & 0.48 & 0.84 & & \\
\hline Item5 & 5 & 1.31 & 2 & 4.64 & 1.31 & 0.11 & -0.32 & 0.86 & & \\
\hline Item6 & 6 & 1.32 & 1 & 5.09 & 1.32 & 0.55 & 0.59 & 0.84 & & \multirow{3}{*}{$\begin{array}{l}\text { 2. Using evidence and } \\
\text { cognitive expertise } \\
0.78\end{array}$} \\
\hline Item7 & 5 & 1.05 & 1 & 5.06 & 1.05 & 0.48 & 0.51 & 0.84 & & \\
\hline Item8 & 5 & 1.13 & 1 & 4.45 & 1.13 & 0.63 & 0.67 & 0.83 & & \\
\hline Item9 & 5 & 1.07 & 2 & 4.27 & 1.07 & 0.63 & 0.64 & 0.83 & & \multirow{7}{*}{$\begin{array}{l}\text { 3. Individualizing care } \\
0.80\end{array}$} \\
\hline Item10 & 5 & 0.88 & 1 & 4.77 & 0.88 & 0.48 & 0.51 & 0.84 & & \\
\hline Item11 & 4 & 1.29 & 2 & 3.62 & 1.29 & 0.52 & 0.51 & 0.84 & & \\
\hline Item12 & 4 & 1.37 & 2 & 3.59 & 1.37 & 0.59 & 0.58 & 0.83 & & \\
\hline Item13 & 4 & 1.12 & 2 & 4.16 & 1.12 & 0.34 & 0.34 & 0.85 & & \\
\hline Item14 & 4 & 1.46 & 3 & 4.26 & 1.46 & 0.35 & 0.37 & 0.85 & & \\
\hline Item15 & 4 & 1.18 & 2 & 4.15 & 1.18 & 0.73 & 0.73 & 0.83 & & \\
\hline
\end{tabular}

The outcomes confirm that this Dutch version of the POPAC scale is a valid and reliable instrument for measuring person-centred care and the quality of care of people with dementia in acute care $[10,19,25]$.

The results obtained from the factor analysis with three factors were comparable with those from earlier research $[10,19,25]$. All of the earlier studies derived a three-factor solution whereby Nilsson found that Cronbach's alpha values of Subscales 2 (using evidence and cognitive expertise) and 3 (using evidence and cognitive expertise) did not reach the necessary cutoff point of 0.7 [10]. Grealish used an exploratory factor analysis because the items did not meet the predetermined cutoff points for using confirmatory factor analysis [25]. They created a revised version of the instrument in which

Table 4 Fit indices

\begin{tabular}{ll}
\hline Metric & Value \\
\hline Comparative Fit Index (CFI) & 0.89 \\
Root mean square error of approximation (RMSEA) & 0.08 \\
RMSEA 90\% Cl lower bound & 0.06 \\
RMSEA 90\% Cl upper bound & 0.09 \\
RMSEA p-value & 0.01 \\
Standardized root mean square residual (SRMR) & 0.06 \\
Hoelter's critical N ( $\mathrm{a}=.05)$ & 106.88 \\
Goodness of fit index (GFI) & 0.99 \\
Expected cross validation index (ECVI) & 1.64 \\
\hline
\end{tabular}

Item 5, concerning leaving people with cognitive impairments alone in the ward, was deleted, and several items were grouped into another subscale. The model fit confirmed the three-factor solution. That is, the Chi-square rejected the model. However, this test has been found to be unreliable for small sample sizes [35]. The CFI indicated a nearly acceptable model fit, as with Nilsson and Grealish, who reported CFIs of 0.88 and 0.90 , respectively $[10,25]$. The RMSEA and the SRMR suggested an acceptable model fit [35]. However, the findings confirmed the three-dimensional structure suggested by previous research. The loadings of the items indicate that these are strong associations with each of the factors. In addition, the factor correlations also indicated that there were strong associations, which indicated that the factors were strongly associated with one general factor of the POPAC scale. Future research is necessary to elucidate the scientific benefits of distinguishing three factors in explaining person-centred care over that of a single generic POPAC factor. The Dutch version of the POPAC scale has similar results as the Edvardsson and Nilsson study $[10,19]$. Grealish assigned three variables to other subscales [25]. In the current study, evidence was found that the POPAC has psychometric properties very similar to those previously reported in the literature. For this reason, the POPAC can be applied in the Netherlands as three separate subscales as well as a total scale measuring the level of person-centred care.

Furthermore, Cronbach's alpha of 0.86 corresponds with earlier research in which the internal consistency 
Table 5 Factor loadings

\begin{tabular}{|c|c|c|c|c|c|c|c|c|}
\hline \multicolumn{9}{|c|}{ Factor loadings } \\
\hline \multirow[b]{2}{*}{ Factor } & \multirow[b]{2}{*}{ Indicator } & \multirow[b]{2}{*}{ Symbol } & \multirow[b]{2}{*}{ Estimate } & \multirow[b]{2}{*}{ Std. Error } & \multirow[b]{2}{*}{ z-value } & \multirow[b]{2}{*}{$\mathbf{p}$} & \multicolumn{2}{|c|}{ 95\% Confidence Interval } \\
\hline & & & & & & & Lower & Upper \\
\hline \multirow[t]{5}{*}{ Factor 1} & Item 1 & $\lambda 11$ & 0.675 & 0.117 & 5.754 & $<.001$ & 0.445 & 0.905 \\
\hline & Item2 & $\lambda 12$ & 0.711 & 0.095 & 7.465 & $<.001$ & 0.524 & 0.898 \\
\hline & Item3 & $\lambda 13$ & 0.649 & 0.094 & 6.944 & $<.001$ & 0.466 & 0.833 \\
\hline & Item4 & $\lambda 14$ & 0.641 & 0.106 & 6.058 & $<.001$ & 0.434 & 0.849 \\
\hline & Item5 & $\lambda 15$ & 0.057 & 0.106 & 0.538 & 0.590 & -0.150 & 0.264 \\
\hline \multirow[t]{3}{*}{ Factor 2} & Item6 & $\lambda 21$ & 1.000 & 0.127 & 7.878 & $<.001$ & 0.751 & 1.249 \\
\hline & Item7 & $\lambda 22$ & 0.671 & 0.098 & 6.814 & $<.001$ & 0.478 & 0.864 \\
\hline & Item8 & $\lambda 23$ & 0.899 & 0.098 & 9.176 & $<.001$ & 0.707 & 1.091 \\
\hline \multirow[t]{7}{*}{ Factor 3} & Item9 & $\lambda 31$ & 0.756 & 0.078 & 9.706 & $<.001$ & 0.603 & 0.909 \\
\hline & Item10 & $\lambda 32$ & 0.496 & 0.069 & 7.171 & $<.001$ & 0.360 & 0.631 \\
\hline & Item11 & $\lambda 33$ & 0.753 & 0.099 & 7.589 & $<.001$ & 0.559 & 0.948 \\
\hline & Item12 & $\lambda 34$ & 0.930 & 0.092 & 10.120 & $<.001$ & 0.750 & 1.110 \\
\hline & Item13 & $\lambda 35$ & 0.501 & 0.085 & 5.891 & $<.001$ & 0.334 & 0.668 \\
\hline & Item14 & $\lambda 36$ & 0.606 & 0.127 & 4.790 & $<.001$ & 0.358 & 0.854 \\
\hline & Item15 & $\lambda 37$ & 0.948 & 0.078 & 12.198 & $<.001$ & 0.796 & 1.100 \\
\hline
\end{tabular}

varies from 0.83 to $0.87[10,19,25]$. Additionally, this research confirms that, statistically, Item 5 (about leaving patients with cognitive impairments alone), which is on the 'Using cognitive assessments and care interventions' subscale, could be deleted to improve the instrument's internal consistency. This is because this subscale has an internal consistency of 0.6 , which is lower than the cutoff of $0.7[26,27]$. Instead of deleting this item, the authors suggest rephrasing it into a positively worded item. It is the only negatively formulated item, which may influence the outcomes. The background of the instrument's construction can provide direction in changing the focus of this question. Nurses are always present in the hospital ward, so they do not experience leaving patients by themselves. However, this does not mean that people with dementia are always visible to nurses and monitored when needed, which might influence care. Our suggestion is to reformulate this question from:

"We leave older people with cognitive impairments alone in the ward."

to:

"We make sure older people with cognitive impairments are not left alone in the ward."

The mean scores in our study were higher than the scores in earlier studies. A higher score reflects a higher level of the construct of person-centred care [19]. This score can partly be explained by the obtained high score found for Item 1 regarding assessing cognitive status. In the Netherlands, assessing cognition is a criterion on which hospital care quality is judged, which might have influenced this positive outcome.

Scores on the POPAC scale among a sample of nurses can be utilized to measure the level of person-centred care for people with dementia in hospitals. Nursing professionals and nursing managers can use the outcomes as indicators to determine which areas of care can be improved in their ward [36]. Additionally, the POPAC scale can be used in the education of nurses and nursing students to create awareness of person-centred care. The POPAC scale is applicable in research on personcentred care, for example, to investigate if a relationship exists between the outcomes of the POPAC scale and complications such as falls, poor hydration and nutrition, delirium, infection, and functional decline. It can also be used to determine whether there is a relation between the level of person-centredness of the care and the length of the hospital stay. In brief, the POPAC scale can be applied to investigate various important research questions regarding interventions for people with cognitive impairment in acute wards. The authors will use this instrument to determine nurses' perceptions of personcentred care for people with dementia.

\section{Limitations}

The POPAC scale is a relatively novel instrument, and its validity and reliability need to be further developed. There is no gold standard available to compare the results with. This study aimed to measure the validity by using factor analysis, as in previous studies. This was 


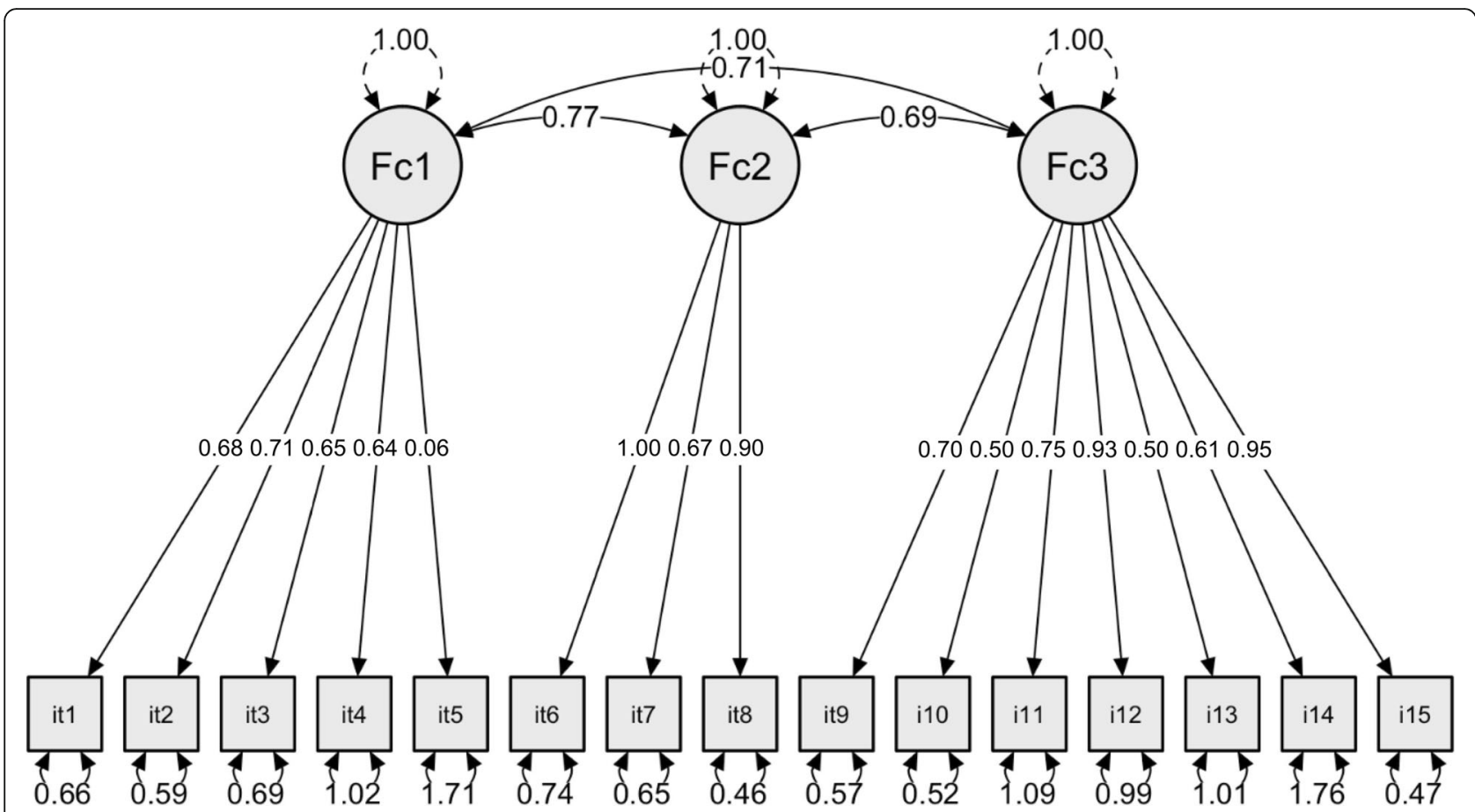

Fig. 1 Model with factor loadings, residual variances, and factor covariances $(n=159)$

done using one group. To improve construct validity, the authors suggest using other methods to strengthen the theoretical basis, such as item response theory, the use of multiple groups, and a test-retest construction.

Our study had a lower response rate $(33 \%)$ in the hospital setting than those of previous studies, e.g., 59\% [19], 51\% [10], and 54.3\% [25], possibly due to the different methods of recruiting responders. There were two primary aspects. On the one hand, nursing managers did not always want to cooperate because there were only a small number of people with dementia in their ward, or they perceived no added value in the study. This could result in a nonresponse bias and affect the external validity of the study. The nonresponse may have caused some bias in the direction of the null. However, since our results were mainly in line with those previously found in the literature, we consider this bias to be relatively weak.

By using a convenience sample, participating nurses with a high affinity for the topic may be overrepresented. This leads to a limitation of the external validity and, consequently, the generalization. Since the recruitment was rather general, yielding a rather broad sample of participants, we expect the results to be generalizable for the setting of general hospitals. In future research, it may be useful to validate actual care provision and behaviour in practical working situations. However, the combination of nurses from hospitals and via social media provided a significant scope of the Netherlands.
The questionnaire was conducted in combination with another lengthy questionnaire. The numerous questions negatively influenced the motivations to complete the questionnaire, which could have caused missing information. This may affect internal validity negatively. We used different orders of the questionnaire to prevent this bias.

\section{Conclusions}

The findings of this study confirm the validity and reliability of the Dutch version of the POPAC scale. However, the results provide grounds for further research on the instrument's dimensionality with a rephrased Item 5 . The results can help nursing managers improve personcentred care in hospitals for people with dementia. The authors advise using total sum scores for interpretation of the scale for national and international comparison. Further research can provide insight into the relationship of person-centred care with the quality of care and nurse-sensitive outcomes, such as preventing complications hospital stay length.

\section{Implications for nursing practice}

The results are of significance for nurses in facilitating the improvement of care for people with dementia. The instrument can be used to hold reflective discussions in clinical settings about the extent to which nurses can perform person-centred care and how they can improve this care. This study's findings also enable the broader 
use of the POPAC scale: a total sum score can be calculated and consequently used to determine and interpret the level of person-centred care. Person-centred care and evidence-based nursing are important ingredients for high-quality nursing care for people with cognitive impairments. Therefore, the instrument is easy for nurses to use as an instrument for practice improvement. Furthermore, nurses can employ the results of the POPAC scale for benchmarking the level of personcentred care at a hospital as well as on a national or international level.

\section{Supplementary Information}

The online version contains supplementary material available at https://doi. org/10.1186/s12913-020-06048-x.

Additional file 1. Dutch version of the POPAC scale.

\section{Abbreviations}

CFA: Confirmatory Factor Analysis; CFI: Comparative Fit Index; Cl: Confidence interval; COSMIN: Consensus-based Standards for the selection of health status Measurement Instruments; POPAC: Person-centred care of Older People with cognitive impairment in Acute Care; RMSEA: Root Mean Square Error of Approximation; SD: Standard deviation; SRMR: Standardized Root Mean-square Residual

\section{Acknowledgements}

The authors would like to thank all participating nurses for completing the questionnaires and all contact persons in the hospitals for their help with distributing the questionnaires.

\section{Authors' contributions}

AKP, EJF, and PFR were responsible for the study design. AKP and EJP were responsible for the translation process. AKP performed the data collection. AKP and WK contributed to the data analysis and interpretation of the data. AKP, EJP, WK, DE, and PFR were involved in drafting and revising the manuscript critically for important intellectual content and gave final approval of the version to be published.

\section{Authors' information}

AKP: RN, MSC, Ph.D.-candidate.

EJF: Ph.D. Professor.

WK: Ph.D. Professor.

ED: RN, Ph.D. Professor.

PFR: Ph.D. Professor

\section{Funding}

This research received no specific grant from any funding agency in the public, commercial, or not-for-profit sectors.

\section{Availability of data and materials}

The datasets generated and analysed during the current study are not publicly available, as more papers will be written based on this dataset. The corresponding author can provide data upon reasonable request.

\section{Ethics approval and consent to participate}

The study was performed following the Helsinki declaration, and all of the participants provided written informed consent before filling out the questionnaire. Nurses had an option to choose whether the results would also be available for further research. The Medical Ethical Committee of the University Medical Centre Groningen considered approval unnecessary (decision M17.221048) because the questionnaire was intended for staff. The questionnaire was completely anonymous; no one could be identified based on the results.
Consent for publication

Not applicable.

\section{Competing interests}

The authors declare that they have no competing interests.

\section{Author details}

${ }^{1} \mathrm{NHL}$ Stenden University of Applied Sciences, Rengerslaan 8-10, Postbox 1298, 8900, CG, Leeuwarden, The Netherlands. ${ }^{2}$ Health Sciences-Nursing Science \& Education University of Groningen \& University Medical Center Groningen, Hanzeplein 1, Postbox 30.001, 9700, RB, Groningen, The Netherlands. ${ }^{3}$ University Medical Center Groningen, Groningen, The Netherlands. ${ }^{4}$ Hanze University of Applied Sciences, Eyssoniusplein 18, 9714, CE, Groningen, The Netherlands. ${ }^{5}$ School of Nursing and Midwifery, La Trobe University, Level 4, Austin Tower, PO BOX 55555, Heidelberg, Victoria 3084, Australia. ${ }^{6}$ Department of Nursing, Umeå University, 90187 Umeå, Sweden.

Received: 29 January 2020 Accepted: 26 December 2020

Published online: 13 January 2021

\section{References}

1. World Health Organization. Key Facts [Internet]. World Health Organization. 2017. p. 5. Available from: http://www.who.int/news-room/fact-sheets/ detail/dementia.

2. Nederlandse vereniging voor klinische geriatrie. Addendum dementie comorbiditeit in het ziekenhuis 2016-08. Utrecht; 2015.

3. Brooker D, Milosevic S, Evans S, Bruce M, Thompson R. RCN development Programme: transforming dementia Care in Hospitals Evaluation Report [internet]. Worcester; 2014. Available from: http://www.worcester.ac.uk/ documents/FULL_RCN_report_Transforming_dementia_care_in_hospital.pdf.

4. Weitzel T, Robinson S, Barnes MR, Berry TA, Holmes JM, Mercer S, et al. The special needs of the hospitalized patient with dementia. Medsurg Nurs. 2011;20(1):13-8.

5. Gladman J, Porock D. Better Mental Health: Care for Older People with Cognitive Impairment in General Hospitals. Final report NIHR Service Delivery and Organisation programme [Internet]. 2012. Available from: http://www. netscc.ac.uk/netscc/hsdr/files/project/SDO_FR_08-1809-227_V01.pdf.

6. Dewing J, Dijk S. What is the current state of care for older people with dementia in general hospitals? A literature review. Dement Int J Soc Res Pract. 2016;15(1471-3012 (Linking)):106-24 Available from: http://www.ncbi. nlm.nih.gov/pubmed/24459188.

7. Handley M, Bunn F, Goodman C. Dementia-friendly interventions to improve the care of people living with dementia admitted to hospitals: a realist review. BMJ Open. 2017;7(2044-6055 (Linking)):e015257. https://doi. org/10.1136/bmjopen-2016-015257.

8. Fogg C, Griffiths P, Meredith P, Bridges J. Hospital outcomes of older people with cognitive impairment: an integrative review. Int J Geriatr Psychiatry. 2018;33:1177-97.

9. Clissett P, Porock D, Harwood RH, Gladman JRF. The challenges of achieving person-centred care in acute hospitals: a qualitative study of people with dementia and their families. Int J Nurs Stud. 2013;50:1495-503.

10. Nilsson A, Lindkvist M, Rasmussen BH, Edvardsson D. Measuring levels of person-centeredness in acute care of older people with cognitive impairment: evaluation of the POPAC scale. BMC Health ServRes [Internet]. 2013;13(1472-6963 (Linking)):327. [cited 2018 Mar 6]. https://doi.org/10. 1186/1472-6963-13-327.

11. Surr CA, Smith SJ, Crossland J, Robins J. Impact of a person-centred dementia care training programme on hospital staff attitudes, role efficacy and perceptions of caring for people with dementia: A repeated measures study. Int J Nurs Stud. 2016;53(0020-7489 (Linking):144-.

12. The American Geriatrics Society Expert Panel on Person-Centered Care. Person-Centered Care: A Definition and Essential Elements. Am Geriatr Soc. 2016;20(1):15-8.

13. Kitwood T. Towards a Theory of Dementia Care: The Interpersonal Process. Ageing Soc [Internet]. 1993;13(1):51-67. [cited 2020 Jan 13]. https://doi.org/ 10.1017/S0144686X00000647.

14. Kitwood T. Dementia reconsidered: the person comes first. Berkshire, UK: Open Univer- sity Press; 1997.

15. McCormack B, McCance T. Person-Centred Nursing: Theory and Practice. Person-Centred nursing: theory and practice; 2010. p. 1-194. 
16. Borg M, Cardiff S, Dewing J, Jacobs G, Janes N, Karlsson B, et al. Personcentredness - the "state" of the art. Int Pract Dev J [Internet]. 2015:5:1-15 Available from: http://ro.uow.edu.au/smhpapers/3798.

17. McCance T, Gribben B, McCormack B, Laird L. Promoting person-centred practice within acute care: the impact of culture and context on a facilitated practice development programme. Int Pract Dev J. 2013:3(1):1-17.

18. Laird EA, McCance T, McCormack B, Gribben B. Patients' experiences of inhospital care when nursing staffwere engaged in a practice development programme to promote person-centredness: a narrative analysis study. Int J Nurs Stud [Internet]. 2014;52(9):1454-62. Available from:. https://doi.org/10. 1016/j.jijnurstu.2015.05.002.

19. Edvardsson D, Nilsson A, Fetherstonhaugh D, Nay R, Crowe S. The personcentred care of older people with cognitive impairment in acute care scale (POPAC). J Nurs Manag. 2013;21(0966-0429 (Linking)):79-86.

20. Edvardsson D, Fetherstonhaugh D, Nay R, Gibson S. Development and initial testing of the Person-centered Care Assessment Tool (P-CAT). Int Psychogeriatrics [Internet]. 2010;22(1):101-8 Available from: http://www.ncbi. nlm.nih.gov/pubmed/19631005.

21. Suhonen R, Gustafsson ML, Katajisto J, Välimäki M, Leino-Kilpi H. Individualized care scale - Nurse version: A Finnish validation study. J Eval Clin Pract [Internet]. 2010;16(1):145-54. [cited 2019 Nov 1]. https://doi.org/ 10.1111/j.1365-2753.2009.01168.x.

22. Edvardsson D, Sandman PO, Rasmussen B. Construction and psychometric evaluation of the Swedish language person-centred climate questionnaire staff version. J Nurs Manag. 2009;17(7):790-5.

23. Wolverton $\mathrm{CL}$, Lasiter S, Duffy JR, Weaver MT, McDaniel AM. Psychometric testing of the caring assessment tool: administration (CAT-Adm (C)). SAGE Open Med. 2018;6:205031211876073.

24. Slater $P$, Mccance T, Mccormack B. The development and testing of the person-centred practice inventory - staff (PCPI-S). Int J Qual Heal Care. 2017; 29(4):541-7.

25. Grealish L, Chaboyer W, Harbeck E, Edvardsson D. The person-centred care of older people with cognitive impairment in acute care (POPAC) scale psychometric evaluation. J Nurs Manag. 2017;25(0966-0429 (Linking)):139-47.

26. Field A. Discovering Statistics Using IBM SPSS [Internet]. 4TH ed. Michal Carmichael, editor. Discovering Statistics Using SPSS. Los Angeles/London/ New Delhi: Sage Publications, Ltd; 2013. p. 1-916. [cited 2018 Oct 10]. Available from: http://www.fb4all.com/download/ebooks/statistics/ \%23DiscoveringStatistics Using SPSS 2013.pdf.

27. Polit DF, Beck CT. Nursing research generating and assessing evidence for

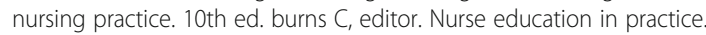
Philadelphia: Wolters Kluwer Health; 2017. p. 784

28. Arafat SMY. Validation study can be a separate study design. Int J Med Sci Public Heal [Internet]. 2016;5(11):2421-2 Available from: http://www. scopemed.org/?mno=225923.

29. Sousa VD, Rojjanasrirat W. Translation, adaptation and validation of instruments or scales for use in cross-cultural health care research: a clear and user-friendly guideline. J Eval Clin Pract. 2011;17(2):268-74.

30. Maneesriwongul W, Dixon JK. Instrument translation process: a methods review. J Adv Nurs [Internet]. 2004;48(2):175-86 Available from: http:// gateway.library.qut.edu.au/login?url=http://search.ebscohost.com/login. aspx?direct=true $\& \mathrm{db}=c 8 h \& A N=2004209102 \&$ site $=$ ehost-live $\&$ scope $=$ site.

31. Boomsma A. Monte Carlo design. Psychometrika [Internet]. 1985;50(2):22942 Available from: https://link-springer-com.proxy-ub.rug.nl/content/pdf/10.1 007\%2FBF02294248.pdf. [cited 2019 Dec 13].

32. Mokkink LB, Terwee CB, Patrick DL, Alonso J, Stratford PW, Knol DL, et al. The COSMIN checklist for assessing the methodological quality of studies on measurement properties of health status measurement instruments: an international Delphi study. Qual Life Res [Internet]. 2010;19(4):539-49 Available from: http://www.ncbi.n/m.nih.gov/pubmed/20169472. [cited 2019 Jun 13]

33. Rosseel Y. Lavaan: An R package for structural equation modeling. J Stat Softw. 2012:48(2):1-36
34. Schreiber JB. Modeling and Confirmatory Factor Analysis Results : A Review. Th J Educ Res [Internet]. 2006:99(09):323-37 Available from: https:// steinhardtapps.es.its.nyu.edu/create/courses/3311/reading/7-Reporting_ SEM_and_CFA_Schreiber_Stage_King_Nora_Barlow_.pdf. [cited 2019 Nov 22].

35. Harrington D. Confirmatory Factor Analysis [Internet]. Confirmatory Factor Analysis; 2009. p. 1-128. Available from: www.oxfordscholarship.com. [cited 2019 Nov 25].

36. Kodama $Y$, Fukahori $\mathrm{H}$. Nurse managers' attributes to promote change in their wards: a qualitative study. Nurs Open. 2017;4(4):209-17.

\section{Publisher's Note}

Springer Nature remains neutral with regard to jurisdictional claims in published maps and institutional affiliations.
Ready to submit your research? Choose BMC and benefit from:

- fast, convenient online submission

- thorough peer review by experienced researchers in your field

- rapid publication on acceptance

- support for research data, including large and complex data types

- gold Open Access which fosters wider collaboration and increased citations

- maximum visibility for your research: over $100 \mathrm{M}$ website views per year

At $\mathrm{BMC}$, research is always in progress.

Learn more biomedcentral.com/submissions 